Johnson deplored the combination of subject matter as gratuitous. This usage has become commonplace. In Britain mode and modality are creeping into Medspeak descriptions such as treatment modality, which is especially popular in the United States. Modality adds nothing to treatment.

Further scope is offered to Medspeakers by the use of "non words" such as context, situation, basically, and essentially. One often sees on a haematology report "essentially normal film"a type of Haemspeak. Does this mean that the film is "perfectly normal," or "more or less normal" ? Liberal larding of phrases with basically adds nothing but a suspicion that all is not what it purports to be. Although Medspeak's widespread use of situation and context is relatively meaningless, they may be used to relieve linguistic monotony-on the one hand the Medspeak context and on the other the Medspeak situation.

Depersonalisation in Medspeak is inevitable. Patients become clinical material or bed number six. Doctors and nurses are health care professionals, their work being health care delivery. As Medspeak becomes too terse these stacked nouns (a useful Germanic technique) restore the balance between economy and prolixity.

\section{Syntactical choice and linguistic dilemmas}

So in erudite circles where advanced Medspeak is used syntactical choices and linguistic dilemmas exist. What should the British Medspeaker do? Resist temptation, or follow his
American cousin by ceasing to be logical and becoming logic? The final solution to this ongoing Machiavellian Medspeak dilemma situation will be the eventual fusion of British and American Medspeak.

Not the least pleasure of a living language is borrowing words from other disciplines and distorting their meaning. Naturally confusion can result when the non-initiate tries to panhandle the difference between the Medspeak meaning and the Real meaning of a word. Parameter to the scientists means a constant factor, but to the Medspeaker a variable. To the zoologist a monitor is a lizard but to the Medspeaker either a machine or a verb.

Medspeak humour is also largely derived from unintentional abuse of medical jargon by the non-medical world: the Medspeak malapropism. Statements such as "the Government's schizophrenic attitude towards the railways" would have undoubtedly interested Freud. Patients are a good source of Medspeak malapropisms when they talk of their deferred pain, their prostrate gland, their mother's discalated hip, and their infested surgical wound. Similarly, secretarial mishaps can cause delight or horror as cerebral spondylosis, serous anguinous fluid, senile dimension, or pseudex atrophy rattle off the typewriters-all, no doubt, the result of a dysarticulating doctor on his dictaphone.

Medspeak is unlikely ever to become boring for the user. It will continue to evolve. And it does not matter what we say among ourselves, provided that we layspeak properly to the patients.

(Accepted 23 fune 1981)

\title{
An anachronistic treatment for asthma
}

\author{
J DEARLOVE，A P VERGUEI， N BIRKIN， P LATHAM
}

\begin{abstract}
Dry cupping is an ancient practice that died out in England over a hundred years ago. In certain cultures it survives and if not recognised can lead to a little diagnostic confusion.
\end{abstract}

\section{Introduction}

We saw two Russian girls who had been unsuccessfully treated for their asthma by cupping. This ancient practice survives in many cultures, and can result in unusual bruising, which in children may lead to an erroneous diagnosis. Because of this point, and its interesting history, we report the following cases.

\section{Case histories}

Case 1-A 14-year-old Russian girl presented with acute asthma. Examination showed many fresh bruises on her back. Her mother

Paediatric Department, Charing Cross Hospital, London W6 8RF

J DEARLOVE, $\operatorname{FRCP}(C)$, MRCP, senior registrar

N BIRKIN, MB, BS, lecturer

P LATHAM, MRCP, senior registrar

Embassy of the USSR, London W8

A P VERGUEI, MD, head, medical service explained that these were due to the application of cups to treat her dyspnoea (fig).

Case 2-A 6-year-old girl also presented with several bruises. Her mother thought that cupping "drew the congestion out of her chest, and made the blood flow faster." As the casualty officer commented, unless one had seen a similar case before it would have been easy to assume, purely on the appearance of the bruises, that this was a case of child abuse.

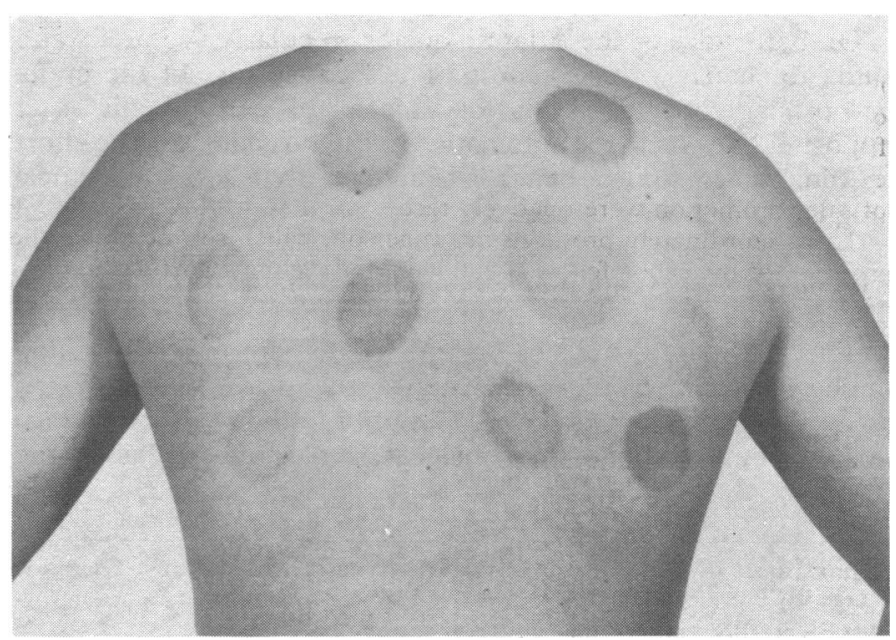

Bruises caused by cupping in a 14-year-old girl. 


\section{Comment}

Dry cupping is a technique of bruising the skin painlessly. The most effective method is to rinse out the bottom of a glass with methylated spirits, set it alight, and evert the glass over the skin. The flame exhausts the supply of oxygen, causing a partial vacuum, and the skin is sucked into the mouth of the glass.' One of us (JD) found it an easy technique to perform and surprisingly painless. If the glass is left in position for about 10 minutes the skin capillaries burst and a bruise results. Occasionally, the skin is scarified before cupping-wet cupping-and the resulting blood loss can be impressive. In the past wet cupping was often used instead of leeches, and the three processes of cupping, scarification, and blood letting are intimately connected in the folk medical tradition. ${ }^{2}$ Hippocrates, ${ }^{3}$ Galen, and Celsus all used cupping, as did Rhazes, who specifically mentions its use in children. ${ }^{4}$ Avicenna regarded the indications for cupping as very specific, one being that cupping enables the inflammation to move either to a less vital organ or to the surface of the body, ${ }^{5}$ a point that was instinctively sensed by the mother of our patient. By the eighteenth century, however, the practice had fallen into disrepute. It was relegated to bath attendants, who regarded the process of scarification in the same light as we regard tattooing. ${ }^{6}$ This debasement of the art prompted the cuppers of the London teaching hospitals to write eloquently of its uses. Mr Mapleson at the Westminster Hospital listed (in a private publication) 45 conditions that would respond to cupping, including asthma. By the time Hyde Salter had published his magnum opus on asthma, however, the use of cupping and bleeding was declining. Then, in 1861, Count Cavour was bled to death by his overenthusiastic physicians. The avoidable death of the man who forged modern Italy at the pinnacle of his political career prompted the $B M F$ to write scathingly about the Italian physicians' "routine, antiquated, and mediaeval method of curing disease by bleeding to death their patients." " And in 1875 the first historical account of bleeding was published in the same journal. ${ }^{8}$

Although both our cases offer an intriguing historical perspective, it is inaccurate to view them purely from the modern therapeutic standpoint of cupping as a treatment for asthma. The technique of cupping antedates Hippocrates' symptomatic view of asthma as an illness characterised by panting, ${ }^{9}$ and it is curious that as the practice of cupping persists, so theories then arise to explain its efficacy. This is true even today. Cupping, scarification, and moxabustion were used in Russian villages by non-medical practitioners, or Babas, as well as by members of the patient's family. The practice survives today in the forms of dry cupping (sukhie banki) or the application of mustard papers to the child's back. ${ }^{10}$ Dry cupping is mainly used in myalgias and chest problems, particularly with children. This form of treatment is known as righz or counter-irritant treatment. The aim of any counter irritant is to stimulate the dermatome that shares the same root value as the inflamed viscera; the subsequent vasodilatation then aids the healing process, ${ }^{10}$ a view similar to Gillies's theories in $1895,{ }^{11}$ except that it is expressed in contemporary language. Even so, the last serious assessment of dry cupping in children with chest disease was in $1941 .^{12}$

Despite its eminent historical pedigree, cupping in a Russian village in the late twentieth century is probably a ritual that has stronger cultural roots than its medical raison d'être. Clearly many Russian parents regard the cupping of their children as positively useful, and avoid frightening their children by only cupping on the back, as with both our patients. Nevertheless, up to $40 \mathrm{ml}$ of blood may be lost into the skin by this method, ${ }^{10}$ and clearly in small children the practice could be dangerous. Finally, although our patients are well managed with oral bronchodilators, their mothers still insist on the efficacy of their home treatment.

We thank the staff at the Wellcome Institute for the History of Medicine for their help; Dr John Gabbay at the Wellcome Unit for the History of Medicine at Cambridge, for his useful advice; and $\mathrm{Dr}$ Jolly for his encouragement. Mrs B Longley very kindly prepared this manuscript.

\section{References}

${ }^{1}$ Gubb AS. Cupping, dry and wet. Br Med $\mathcal{F} 1923$; :639.

${ }^{2}$ Brockbank W. Ancient therapeutic arts. London: Heinemann Medical Books, $1954: 68-71$

${ }^{3}$ Hippocrates. Aphorisms V, 40. Vol 4. London: Heinemann Medical Books, $1931: 170$. (Trans: WHS Jones.)

4 Rhazes. A treatise on the smallpox and measles. London: Sydenham Society, 1948:37. (Trans: WA Greenhill.)

${ }^{5}$ Gruner OC. A treatise on the canon of medicine of Avicenna. New York: Augustus M Kelly, 1970:571.

${ }^{6}$ Dionis D. Cours d'operations de Chirurgie demonstrées au Jardin Royal 1708. Quoted in Blood-letting instruments by Davis and Appel. Smithsonian Studies in History and Technology No 41, p 19. Washington. Smithsonian Institute Press, 1979.

${ }^{7}$ Anonymous. This week. $B r$ Med $\mathcal{F} 1861$;i:637.

${ }^{8}$ Clarke WM. On the history of bleeding and the disease in modern practice. Br Med F 1875;ii:67-70.

${ }^{9}$ Hippocrates. Aphorisms VI, 46. Vol 4. London: Heinemann Medical Books, 1931:188. (Trans: WHS Jones.)

10 Gurevitsh G. In: Semashko NA. The big medical encyclopedia. Moscow: Joint Stock Co, 1928:770-4.

11 Gillies C. Counter irritation. London: MacMillan, 1895.

12 Eyvin DG, Kolner RU. The use of cupping in children with chest disease. Paediatrics (Moscow) $1941 ; 2: 20-3$.

(Accepted 7 August 1981)

\section{A time to remember}

The first watch I ever owned, a pocket Ingersoll, cost $7 / 6 \mathrm{~d}$. At least it would have cost $7 / 6 \mathrm{~d}$ had not my father succumbed to the wiles of a high-pressure, door-to-door salesman, who offered the watch free in return for a written undertaking to buy a certain Yorkshire evening paper for a year. This was in the 1920s, when such methods of sales promotion were relatively rare.

I was inordinately proud of my Ingersoll, which set me above the majority of my schoolfellows, who were for the most part a watchless society. It had a bold tick, audible at a range of at least two feet, but truth to tell it was not the best of timekeepers. It was fallible within a daily range of five to 10 minutes either way, but it was its very fallibility which gave me the excuse to open the back every night with my penknife and adjust the movement after the ritual winding. Our relationship was essentially a symbiotic one: it needed me as much as I needed it.

The watch was attached by a leather strap to the lapel of my jacket and worn inside the left breast pocket - a particularly vulnerable position. Nevertheless, it survived unbelievable traumas sustained in innumerable scraps in the school playground and elsewhere. Eventually after three, maybe four, years time and trauma took their

toll: its tick became less bold and then finally it expired. To my intense chagrin it was declared irreparable by the local watchmaker. One Saturday afternoon I walked on my own to a nearby lake, where ceremoniously I cast my good companion into the waters and then stood for a few moments in reverential silence.

Since then I have had a host of timepieces, acquired by purchase, as gifts, or in one instance, as a bequest, but not one have I regarded with anything like the same affection as I did my old Ingersoll. They, too, were fallible in some respect: some failed to keep the time, some failed to keep the date and/or the time, and some just failed.

Today, just to be in the technological swim, I had bought me an attractive-looking, inexpensive, quartz wristwatch. It is driven, I am told, by a minute battery concealed in the works. But there is no tick. In the many months since I possessed it it has neither gained nor lost as much as a second. It requires, therefore, no adjustment, even supposing I knew how this was done. Altogether, it needs me not at all. As a watch it is, of course, perfection: but perfection to any mortal endowed with his fair share of human frailties is always intimidating. And this is precisely the effect this awesome time machine has on me.-HENRY R ROLLIN, retired consultant psychiatrist, Epsom. 